\title{
CARACTERÍSTICAS AGRONÔMICAS E PRODUTIVIDADE DE AMENDOIM EM DIFERENTES ESPAÇAMENTOS E ÉPOCAS DE SEMEADURA NO RECÔNCAVO BAIANO $\left({ }^{1}\right)$
}

\author{
CLOVIS PEREIRA PEIXOTO $\left({ }^{2 *}\right)$; JOAQUIM ALVES GONÇALVES $\left({ }^{3}\right)$; MARIA DE FÁTIMA DA SILVA \\ PINTO PEIXOTO $\left({ }^{2}\right)$; DARCILÚCIA OLIVEIRA DO CARMO $\left({ }^{4}\right)$
}

\begin{abstract}
RESUMO
Avaliou-se o desempenho vegetativo e produtivo de plantas de amendoim (Arachis hypogaea L.) sob diferentes espaçamentos e densidades e em duas épocas de semeadura, tendo como primeira época o início da estação chuvosa (março-junho) e como segunda, o fim do período (julho-outubro) nas condições agroclimáticas do Recôncavo Baiano. O trabalho foi desenvolvido no campo experimental do Centro de Ciências Agrárias e Biológicas da Universidade Federal do Recôncavo da Bahia, no delineamento de blocos casualizados em esquema fatorial $3 \times 3+1$; três densidades de plantas: 5,10 , e 15 plantas $\mathrm{m}^{-1}$, três espaçamentos: $0,50 \mathrm{~m}, 0,65 \mathrm{~m}$ e $0,80 \mathrm{~m}$ entrelinhas, com um tratamento testemunha em covas espaçadas de aproximadamente $0,25 \mathrm{~m} \times 0,30 \mathrm{~m}$, com quatro repetições. As características agronômicas: altura final de plantas, número de ramificações finais e número de folhas foram determinados em 10 plantas da parcela útil, enquanto o volume de vagens frescas e a produtividade de vagens e grãos foram determinados com base na população de plantas. Conclui-se que a escolha do arranjo espacial que expressa maior produtividade de vagens e de grãos depende do objetivo comercial do produtor (volume ou massa) e da época de semeadura. A utilização de novos arranjos espaciais pelos agricultores do Recôncavo Baiano, se faz necessário, uma vez que a semeadura em covas $(0,25 \mathrm{~m} \times 0,30 \mathrm{~m})$ mostra-se menos produtiva nas duas épocas.
\end{abstract}

Palavras-chave: Arachis hypogaea, arranjos espaciais, rendimento de amendoim.

\section{ABSTRACT \\ AGRONOMIC CHARACTERISTICS AND YIELD OF PEANUT UNDER DIFFERENT SOWING DATES AND PLANTING ARRANGEMENTS IN THE RECONCAVO REGION OF BAHIA STATE}

The vegetative and productive performance of peanut plants, cultivated under different spacing and planting densities, at two sowings dates, in the raining season (march-june) and by July-October were evaluated in the agro ecologic conditions of the Reconcavo Region of the state of Bahia, Brazil. The experiment was carried out at the Experimental Station of the School of Agronomy, Federal University of Recôncavo of Bahia, in a randomized complete block design, with the following factorial arrangement: $3 \times 3+1$ (three plant densities: 5, 10, and 15 plants $\mathrm{m}^{-1} \mathrm{x}$ three plant spacing: $0.50 \mathrm{~m}, 0.65 \mathrm{~m}$, and $0.80 \mathrm{~m}$, plus a control treatment with planting holes of approximately $0.25 \mathrm{~m} \times 0.30 \mathrm{~m}$, with four replications. The following agronomic characteristics were studied: final plant height, number of final branches, leaf number. Ten plants per plot were sampled for the evaluations, and the volume of fresh pods and grain yield was determined based on the final plant population of each plot. It was concluded that: the decision on the plant arrangement that gives the highest yield of pods and grains depends on the farmer's commercial interests (volume or mass) and also on the sowing dates. The utilization of new planting arrangements by the farmers from the Reconcavo region of Bahia is necessary, since the conventional planting system in holes $(0.25 \times 0.30)$, presents the lowest productivity, at both sowings dates.

Key words: Arachis hypogaea, peanuts yields.

( $\left.{ }^{1}\right)$ Recebido para publicação em 8 de fevereiro de 2006 e aceito em 27 de março de 2008.

$\left({ }^{2}\right)$ Centro de Ciências Agrárias, Ambientais e Biológicas (CCAAB), UFRB, Campus Universitário, 44380-000 Cruz das Almas (BA), Brasil. E-mail: cppeixot@ufba.br $\left(^{*}\right)$ Autor correspondente.

$\left({ }^{3}\right)$ J. L. Comercial Agroquímica Ltda, 43813-000 Candeias (BA), Brasil.

(4) Federação dos Trabalhadores da Agricultura no Estado da Bahia (FETAG), Cruz das Almas (BA), Brasil. 


\section{INTRODUÇÃO}

O amendoim (Arachis hypogaea L.) é uma das principais oleaginosas cultivadas no Brasil e no mundo e considerada uma das mais importantes culturas entre as leguminosas, ao lado do feijão e da soja (Henriques Neto et al., 1998). O Estado de São Paulo se destaca como o maior produtor nacional, sendo responsável por $85 \%$ da produção brasileira (Kasai et al., 1999). No Nordeste brasileiro, os principais Estados produtores são Bahia, Sergipe, Paraíba e Ceará, com produtividade média ainda muito baixa. Embora esta produção seja restrita aos pequenos produtores em sua maioria, esta Região possui condições agroecológicas favoráveis para a obtenção de vagens e grãos de boa qualidade, quanto às condições fitossanitárias e sensoriais.

Na Bahia, em especial no Recôncavo Baiano, cerca de $80 \%$ da produção obtida é destinada ao mercado de consumo in natura, como amendoim torrado ou cozido, gerando empregos diretos e indiretos, uma vez que o produto na sua maioria é comercializado em feiras livres, festas juninas, festas de largos, praias, etc., conferindo grande importância no contexto socioeconômico dessa Região. Contudo, o sistema de produção utilizado pelos agricultores ainda é bem distante dos padrões de uma exploração moderna com predominância do cultivo em pequenas áreas, empregando covas espaçadas irregularmente e feitas com enxadas, sem qualquer adubação e nos meses mais chuvosos e úmidos que coincide com o outono, ou seja, março, abril, maio e junho.

O potencial de produção do amendoim é determinado geneticamente e quanto deste potencial vai ser exteriorizado depende de fatores limitantes que estarão atuando em algum momento durante o ciclo da cultura. No aspecto fenológico, as fases de crescimento e desenvolvimento entre os genótipos do tipo Valência, ao qual pertence a cultivar Vagem Lisa, são particularmente definidas, mas podem variar dependendo do local e das condições climáticas principalmente temperatura e umidade (SANTOS et al., 1997b).

Observa-se no amendoim característica de plasticidade, ou seja, possui mecanismos fisiológicos que lhe conferem a capacidade de se desenvolver em ambientes edafoclimáticos adversos por meio de modificações na morfologia e na produção da planta. Em estudo conjunto de quatro experimentos NAKAGAWA et al. $(1994 ; 2000)$, verificaram que a densidade de 20 sementes $\mathrm{m}^{-1}$, foi superior em produtividade a de 10 sementes $\mathrm{m}^{-1}$, e que ambas foram semelhantes à densidade de 15 plantas $\mathrm{m}^{-1}$.

Em amendoim, aumentando-se a população de plantas, conseguem-se aumentos na produtividade, entretanto, tais ganhos ocorrem até um determinado número de plantas por unidade de área (NAKAGAWA et al., 2000), obtendo-se resultados diferenciados em função do cultivar e das condições do meio (Mozingo e Wright, 1994). Silva e Beltrão (2000), trabalhando com diferentes populações, verificaram que nas maiores densidades, houve menor número de ramos por planta ocorrendo o inverso com as menores populações.

A época de semeadura é definida por um conjunto de fatores ambientais que, além de afetar a produtividade, afeta também a arquitetura e o desenvolvimento da planta. Semeaduras em épocas inadequadas podem causar reduções drásticas na produtividade de vagens e grãos, devido a alterações na altura da planta, no número de ramificações, no diâmetro do caule e no acamamento (Регхото, 1998; Peixoto et al., 2002).

Segundo Peixoto et al. (2002) ao optar por uma determinada época de semeadura, o produtor está escolhendo uma determinada combinação entre a fenologia da cultura e a distribuição dos elementos do clima na região de produção que poderá resultar em elevada ou reduzida produtividade. O efeito desses fatores pode ser minimizado pela mudança de tecnologia prevendo adoção de um conjunto de práticas de manejo como a semeadura mecânica em linhas, o adensamento de plantas dentro das linhas e épocas de semeadura em diferentes estações do ano, fazendo com que a comunidade de plantas tenha o melhor aproveitamento possível dos recursos ambientais, influenciando diretamente na produtividade de vagens e grãos.

Com base na hipótese de que uma combinação de densidade e espaçamento ideal dentro de uma época de semeadura mais favorável, expressa maior produtividade de vagens e grãos, este trabalho objetivou avaliar características agronômicas e a produtividade de amendoim da cultivar Vagem Lisa, em diferentes arranjos espaciais, em duas épocas de semeadura nas condições agroecológicas do Recôncavo Baiano, mais especificamente, no município de Cruz das Almas (BA).

\section{MATERIAL E MÉTODOS}

O experimento foi realizado no Campo Experimental do Centro de Ciências Agrárias, Ambientais e Biológicas, Universidade Federal do Recôncavo da Bahia, localizado em Cruz das Almas (BA), situado a $12^{\circ} 40^{\prime} 19^{\prime \prime}$ de Latitude Sul e $39^{\circ} 06^{\prime} 22^{\prime \prime}$ de Longitude Oeste de Greenwich, tendo $220 \mathrm{~m}$ de altitude. O clima é tropical quente úmido, Aw a Am, segundo a classificação de Köppen. A pluviosidade 
média anual é de $1.224 \mathrm{~mm}$ e a temperatura média anual é de $24,5^{\circ} \mathrm{C}$, com umidade relativa de $80 \%$ (ALMEIDA, 1999).

Foram estudadas duas épocas de semeadura. A instalação do primeiro experimento ocorreu em julho de 2003, período considerado pouco apropriado pelos agricultores da região do Recôncavo Baiano, uma vez que coincide com a estação final das chuvas. A segunda época de semeadura foi em março do ano seguinte (2004), coincidindo com o início da estação chuvosa, considerada normal ou convencional e mais utilizada pelos agricultores, uma vez que reúne as condições agroclimáticas mais favoráveis à cultura do amendoim.

A cultivar utilizada foi Vagem Lisa (land race): cultivar local - do grupo Valência, recomendada para a Região Nordeste do Brasil e bastante utilizada no Recôncavo Baiano, e cujas principais características fenológicas são apresentadas na tabela 1 (SANTOS et al., 1997b).

O solo da área experimental é classificado como Latossolo Amarelo álico coeso, " A" moderado, textura franco-argilo-arenoso e relevo plano. É um solo bastante profundo e com horizontes subsuperficiais coesos (REZENDE, 2000). Suas características químicas são apresentadas na tabela 2 e foram determinadas no Laboratório de Análises químicas da Embrapa Mandioca e Fruticultura, como base para que se procedesse à correção da acidez e fertilidade.

A calagem foi realizada sessenta dias antes da semeadura nas duas épocas estudadas nas doses de 814 e $319 \mathrm{~kg} \mathrm{ha}^{-1}$, respectivamente, de calcário dolomítico com PRNT de $80 \%$. Esta foi aplicada na sua totalidade e incorporada com uma aração de 25 $\mathrm{cm}$ de profundidade, seguida de uma gradagem.

Em solo preparado convencionalmente, os sulcos e covas para adubação e semeadura foram abertos manualmente, utilizando como instrumento agrícola o sacho. A adubação foi fundamentada na interpretação da análise química do solo, seguindose as recomendações para a cultura do amendoim no Estado da Bahia. Aplicaram-se, uma semana antes da semeadura nas covas e nos sulcos de semeadura, $60 \mathrm{~kg} \mathrm{ha}^{-1}$ de $\mathrm{P}_{2} \mathrm{O}_{5}$ (superfosfato simples) em ambas as épocas e 60 e $20 \mathrm{~kg} \mathrm{ha}^{-1}$ de $\mathrm{K}_{2} \mathrm{O}$ (cloreto de potássio), respectivamente, na primeira e segunda época. Como a área experimental possui um histórico de cultivo de leguminosa não foi utilizada adubação nitrogenada em nenhum momento durante o ciclo da cultura.

Tabela 1. Descrição dos estádios fenológicos das plantas de amendoim do tipo Valência, ao qual pertence a cultivar Vagem Lisa (Land race)

\begin{tabular}{lll}
\hline Símbolo & Denominação & Descrição \\
\hline E & Emergência & 6 dias após a semeadura (DAS) $\left(^{1}\right)$ \\
FT & Primeiras folhas tetrafoliadas & 9 DAS \\
PR & Primeiros ramos & 14 DAS \\
FL & Florescimento & 29 DAS \\
AG & Aparecimento do ginóforo & 36 DAS \\
ALG & Alongamento do ginóforo & 3 dias após a fase em que o ginóforo encontrava-se \\
& & com mais de 1 cm do seu crescimento geotrópico \\
FV & Formação de vagem (frutificação) & 47 DAS \\
FF & Final da floração & 74 DAS \\
MCV & Maturação completa da vagem & 99 DAS
\end{tabular}

Fonte: SANTOS et al. (1997b), adaptado pelo autor.

(1) O número de dias após a semeadura (DAS) pode variar de acordo com as condições climáticas.

Tabela 2. Análise química $\left({ }^{1}\right)$ do solo da área experimental na profundidade de $0-20 \mathrm{~cm}$, nas duas estações de crescimento.

\begin{tabular}{|c|c|c|c|c|c|c|c|c|c|c|c|c|}
\hline Época & $\mathrm{pH}$ & M.O. & $\mathrm{P}$ & K & $\mathrm{Ca}$ & $\mathrm{Mg}$ & $\mathrm{Ca}+\mathrm{Mg}$ & $\mathrm{Al}$ & $\mathrm{H}+\mathrm{Al}$ & $S$ & СТC & V \\
\hline & $\mathrm{CaCl} 2$ & $\mathrm{~g} \mathrm{dm}-3$ & $\mathrm{mg} \mathrm{dm}-3$ & & & & $\mathrm{cmolc}$ & $m-3$ & & & - & $\%$ \\
\hline Julho & 5,5 & 2,63 & 9,0 & 0,04 & 0,6 & 0,6 & 1,2 & 0,4 & 1,98 & 1,28 & 3,26 & 39,17 \\
\hline Março & 5,2 & 20,26 & 10,0 & 0,20 & 1,6 & 0,6 & 2,2 & 0,1 & 2,09 & 2,47 & 4,56 & 54,16 \\
\hline
\end{tabular}

${ }^{(1)}$ Laboratório de Análises Químicas de Solo da Embrapa Mandioca e Fruticultura. 
As parcelas foram instaladas utilizando-se os diferentes espaçamentos e densidades nas linhas e a semeadura em covas (testemunha), como tratamento convencional e adotado pelos agricultores. As sementes não receberam nenhum tipo de tratamento antifúngico ou inoculação. Procedeu-se a semeadura manual, adicionando-se $25 \%$ a mais da densidade pretendida, efetuando-se o desbaste 15 dias após a semeadura, a fim de garantir o estande pretendido.

Na primeira época de semeadura, não houve necessidade de suplementação hídrica. Entretanto, na segunda época, no período posterior á semeadura, fezse necessária a irrigação das parcelas para garantir umidade suficiente à germinação das sementes e emergência das plântulas, ou quando se fez necessário nas demais fases fenológicas, garantindo o pleno desenvolvimento vegetativo e reprodutivo das plantas.

O experimento foi desenvolvido no delineamento em blocos casualizados, em esquema fatorial $3 \times 3+1$, com quatro repetições. Utilizaramse três densidades de semeadura: 5, 10 e 15 sementes por metro na linha e espaçamentos entrelinhas de 0,50 $\mathrm{m}, 0,65 \mathrm{~m}, 0,80 \mathrm{~m}$, alem de um tratamento testemunha com covas espaçadas de $0,25 \mathrm{~m} \times 0,30 \mathrm{~m}$ (Tabela 3 ).

Cada unidade experimental foi constituída por seis linhas de semeadura com comprimento de 5,0 m, tendo a distância entre as linhas variado de acordo com o tratamento. A área útil para a obtenção dos valores de produtividade, correspondeu às duas linhas centrais de plantas descontando-se a título de bordadura, 0,50 m de cada extremidade, e a dimensão da parcela útil variou de acordo com o tratamento (Horn et al., 2000). As demais linhas constituíram as bordaduras. Nas parcelas do tratamento realizado em covas a distribuição de semeadura possibilitou selecionar duas linhas que ocupavam a área central da parcela totalizando $9 \mathrm{~m}^{2}$, eliminando também 0,50 $\mathrm{m}$ de bordadura nas extremidades da linha.

Os dados coletados na área útil de cada repetição para as diferentes variáveis foram submetidos à análise de variância. Para efeitos significativos pelo teste $\mathrm{F}$, realizou-se o teste de Tukey a $5 \%$ de probabilidade. Visando à comparação das médias dos tratamentos em relação testemunha absoluta, realizouse o teste de Dunnett a 5\% de probabilidade.

Tabela 3. Descrição da estrutura dos tratamentos nos diferentes arranjos espaciais densidades (D) x espaçamentos (E) de plantas de amendoim, em Cruz das Almas (BA)

\begin{tabular}{lccc}
\hline Tratamentos & Arranjos espaciais & Área explorada por planta & Plantas ha $^{-1}$ \\
\hline & & $\mathrm{m}^{2}$ & $\mathrm{n}^{{ }^{\circ}}$ \\
D1 E2 & $5 \mathrm{pl} \mathrm{m}^{-1} \times 0,65 \mathrm{~m}$ & 0,130 & 76.900 \\
D1 E3 & $5 \mathrm{pl} \mathrm{m}^{-1} \times 0,80 \mathrm{~m}$ & 0,160 & 62.500 \\
D2 E1 & $10 \mathrm{pl} \mathrm{m}^{-1} \times 0,50 \mathrm{~m}$ & 0,050 & 200.000 \\
D2 E2 & $10 \mathrm{pl} \mathrm{m}^{-1} \times 0,65 \mathrm{~m}$ & 0,065 & 153.800 \\
D2 E3 & $10 \mathrm{pl} \mathrm{m}^{-1} \times 0,80 \mathrm{~m}$ & 0,080 & 125.000 \\
D3 E1 & $15 \mathrm{pl} \mathrm{m}^{-1} \times 0,50 \mathrm{~m}$ & 0,033 & 303.000 \\
D3 E2 & $15 \mathrm{pl} \mathrm{m}^{-1} \times 0,65 \mathrm{~m}$ & 0,043 & 232.500 \\
D3 E3 & $15 \mathrm{pl} \mathrm{m}^{-1} \times 0,80 \mathrm{~m}$ & 0,053 & 188.600 \\
AGRIC $\left({ }^{1}\right)$ & $0,25 \mathrm{~m} \mathrm{x}^{2}, 30 \mathrm{~m}$ & 0,075 & 133.300 \\
\hline
\end{tabular}

(1) Tratamento-testemunha.

Com o objetivo de melhor compreensão e interpretação dos resultados relativos às variáveis analisadas estatisticamente, coletaram-se os dados climáticos correspondentes aos valores médios mensais da temperatura do ar, da radiação solar total, umidade relativa e precipitação pluvial total mensal durante o período relativo aos experimentos nas duas épocas de semeadura (Tabela 4).

Acompanhou-se o desenvolvimento fenológico das plantas em cada época de semeadura de acordo com os dados relatados por ConAGin (1960), UMEM (1976) e SANTOS et al. (1997b), que descreveram os estádios de desenvolvimento da planta de amendoim do grupo Valência, no qual se encontra a cultivar Vagem Lisa.

As determinações para avaliar os efeitos dos fatores densidades e espaçamentos, com os arranjos formados nas duas épocas de semeadura, sobre as características agronômicas das plantas de amendoim (altura final de plantas, número de ramificações finais e número de folhas), foram efetuadas em amostras constituídas de 10 plantas, coletadas aleatoriamente em cada parcela útil, por ocasião da plena maturação da cultura. 
O volume de vagens em $\mathrm{L} \mathrm{m}^{-2}$ e a produtividade de vagens e grãos em $\mathrm{kg} \mathrm{ha}^{-1}$ foram determinados com base na população final de plantas existente na área útil de cada parcela. As plantas foram colhidas, e, após uma semana de armazenamento, em temperatura e umidade ambiente, a produtividade de vagens e de grãos de cada parcela foi aferido $\left(\mathrm{kg} \mathrm{parcela}^{-1}\right)$ e transformado em kg ha ${ }^{-1}$.

Devido à não-existência de metodologia específica para determinação da massa de mil grãos, foram separadas 8 subamostras de cem grãos, por parcela, cujas massas foram determinadas em balança com precisão de centésimo de grama. Para determinação da umidade dos grãos produzidos em cada parcela, foi utilizado o método da estufa, a $105^{\circ}$ $\pm 3{ }^{\circ} \mathrm{C}$, por 24 horas, corrigidos para a umidade de $13 \%$, sendo tais procedimentos efetuados segundo prescrições estabelecidas pelas Regras de Análise de Sementes (BRASIL, 1992).

\section{RESULTADOS E DISCUSSÃO}

Os valores médios mensais da temperatura do ar, precipitação pluvial, insolação e a umidade relativa são apresentados na tabela 3 e se referem às principais condições climáticas pelas quais evoluíram os ciclos fenológicos da cultura do amendoim, em cada época de semeadura.

Analisando-se as informações contidas nessa tabela, nota-se que os valores médios dos atributos climatológicos estão próximos das normais climatológicas da região, porém, em análise mais detalhada, pode-se notar que os valores médios da temperatura, a umidade relativa do ar e a insolação, na primeira época de semeadura, foram inferiores em relação à segunda. Quanto à precipitação pluvial, verifica-se que na primeira época os valores foram superiores nos dois primeiros meses, invertendo-se na segunda época, mais especificamente, em maio e junho, quando os valores médios foram mais elevados.

Na primeira época, o período de estiagem coincidiu com a fase reprodutiva da planta, enquanto na segunda época, as menores precipitações pluviais ocorreram na fase vegetativa, influenciando de forma diferenciada no desenvolvimento vegetativo e reprodutivo da planta, como mostra alguns caracteres estudados.

Verificou-se, pelo desenvolvimento da planta, que na primeira época, a emissão de ginóforos ocorreu a partir dos 36 dias após a semeadura, coincidindo com os dados apresentados por SANTOS et al. (1997b), que também verificaram nas plantas de amendoim do tipo Valência (cultivar BRS 151-L7, desenvolvido pela Embrapa Algodão), o aparecimento dessas estruturas no mesmo período. Na segunda época, esse fato ocorreu 30 dias após a semeadura, mostrando precocidade em relação às plantas cultivadas na primeira época.

Segundo Reichardt (1990), a planta de amendoim não é sensível ao fotoperíodo e necessita para o ótimo desenvolvimento, temperatura média entre 22 e $29^{\circ} \mathrm{C}$, com 500 a $700 \mathrm{~mm}$ de chuva, da semeadura à colheita. Os valores médios da temperatura na segunda época de semeadura (março a junho) foram superiores aos da primeira época de semeadura (julho a outubro), principalmente nos dois primeiros meses do cultivo, estando dentro da média da região $\left(24,5{ }^{\circ} \mathrm{C}\right)$ e coincidindo com a faixa considerada ótima da cultura.

Observa-se, ainda, que na primeira época, os valores de temperatura margearam o limite mínimo dessa faixa, principalmente em julho e agosto (Tabela 4), coincidindo com o período de florescimento que se iniciou aos 21 dias após a semeadura, quando as temperaturas um pouco abaixo da média (em torno de $22{ }^{\circ} \mathrm{C}$ ). Esses valores podem ter influenciado na viabilidade do pólen, afetando a fase reprodutiva da cultura, conforme CHOUdHARI et al. (1985), que estudaram a fenologia de genótipos do tipo Valência no verão e no inverno; esses autores constataram que há maior emissão de ginóforos no período mais quente, e mais flores foram polinizadas, fertilizadas e desenvolvidas no verão.

Para Santos et al. (1997b), os aspectos da fenologia, que envolve as fases de crescimento e desenvolvimento da planta de amendoim, são particularmente definidos. Entretanto, podem variar, dependendo do local e das condições climáticas, principalmente temperatura, onde são cultivadas.

Pelo fato de nas características agronômicas do amendoim haver grande variabilidade entre as cultivares, em função das condições ambientais e da população de plantas a que se submetem seus cultivos, sugere-se estudar a associação entre os caracteres, sempre enfatizando a contribuição de cada um, para a produtividade em vagens e grãos.

Com relação à altura final de plantas, a análise de variância revelou diferenças significativas apenas na segunda época, para os fatores densidade $(\mathrm{P}<0,01)$, espaçamento $(P<0,05)$ e para a interação entre eles $(P$ $<0,01)$. Mesmo sem haver diferenças significativas entre os arranjos compostos por densidades e espaçamentos na primeira época, é possível notar (Tabela 5) que em menores densidades houve menores alturas de planta, ocorrendo o inverso com as maiores densidades, provavelmente em decorrência de menor competição intraespecífica, em baixa densidade de plantas. Esses resultados concordam com os observados por HeIFFIG (2000) que verificou nas menores densidades menor altura final de planta. 
Tabela 4. Valores de temperatura média mensal do ar $\left({ }^{\circ} \mathrm{C}\right)$, precipitação pluvial total mensal (mm) insolação (horas/ mês) e umidade relativa do ar (\%) em duas épocas de semeadura de amendoim cv. Vagem Lisa, em Cruz das Almas (BA)

\begin{tabular}{lcccc}
\hline Meses & Temperatura & Precipitação pluvial & Insolação & Umidade relativa do ar \\
\hline & ${ }^{\circ} \mathrm{C}$ & $\mathrm{mm}$ & horas/mês & $\%$ \\
Julho & 22,0 & 133,7 & 114,0 & 85,33 \\
Agosto & 21,9 & 115,8 & 197,1 & 81,33 \\
Setembro & 22,1 & 76,3 & 161,0 & 79,00 \\
Outubro & 23,0 & 13,0 & 77,6 & 71,00 \\
Março & 27,0 & 85,0 & 217,4 & 76,66 \\
Abril & 26,3 & 59,8 & 219,5 & 82,00 \\
Maio & 24,0 & 144,7 & 181,3 & 89,00 \\
Junho & 23,3 & 159,8 & 157,5 & 89,66 \\
\hline
\end{tabular}

Fonte: Estação Agroclimatológica da Embrapa Mandioca e Fruticultura, Cruz das Almas (BA).

Ainda segundo este autor, a competição intraespecífica das plantas pelos fatores do ambiente vai determinar o menor ou maior porte da planta, e dessa forma, sob maiores densidades de planta na linha, há menor disponibilidade de produtos da fotossíntese para o crescimento vegetativo, sendo os fotossimilados destinados ao crescimento das plantas em altura. Segundo Pеiхото et al., (2002), a densidade de plantas na linha é um fator modificador da arquitetura da planta permitindo que estas se adaptem a diferentes condições.

Diferentemente do esperado, essas argumentações não se aplicam à segunda época, quando os resultados mostram que no arranjo formado pela menor densidade $\left(5\right.$ plantas $\left.\mathrm{m}^{-1}\right)$ com o espaçamento de $0,80 \mathrm{~m}$ entre linhas, houve maior altura final de planta $(67 \mathrm{~cm})$ diferindo estatisticamente das demais densidades estudadas, bem como do tratamento do agricultor. Como pode ser observado no teste de Dunnett (Tabela 9), diferiu ainda do espaçamento de $0,50 \mathrm{~m}$, igualando-se estatisticamente ao de $0,65 \mathrm{~m}$, na mesma densidade.

Segundo SANTOS (2000), nas plantas do grupo Valência ao qual pertence a cultivar Vagem Lisa, a altura final é em torno de $45 \mathrm{~cm}$, o que foi observado na primeira época. No entanto, para essa característica, os valores encontrados na segunda época foram superiores, independentemente dos tratamentos estudados, excetuando-se o arranjo de 10 plantas $\mathrm{m}^{-1} \times 0,65 \mathrm{~m}$. Esta diferença pode estar relacionada com a maior disponibilidade dos fatores climáticos como temperatura e insolação (radiação solar) na segunda época, que tornaram o ambiente mais favorável para o desenvolvimento do amendoim (Tabela 4).
Os aspectos fisiológicos da planta estão diretamente relacionados à radiação solar e, principalmente, com a intensidade luminosa que, por sua vez, relaciona-se com a atividade fotossintética, alongamento da haste principal e das ramificações, expansão foliar, nodulação e outras características da planta (CÂmARA, 1998). De acordo com Lima et al. (1981), o amendoim não requer exigências excepcionais quanto ao clima e ao solo, mas sim, apenas calor e umidade para seu desenvolvimento. $\mathrm{O}$ fator que pode estar diretamente envolvido neste caso é a quantidade de radiação interceptada pela cultura nos diferentes arranjos e nas diferentes épocas do ano. O máximo aproveitamento da radiação solar é elemento primordial na exploração agrícola, uma vez que sua transformação e fixação na forma de substâncias fotossintetizadas, constituindo a matéria seca da planta, é o que se busca na agricultura.

Assim, para que a energia disponível seja utilizada intensamente é necessário que haja sua interceptação em alto grau e que as plantas apresentam grande eficiência em transformá-la e fixála, segundo BARNI e BERGAMASCHI (1981). A quantidade de radiação interceptada por uma cultura é função da intensidade da energia radiante que incide sobre a comunidade vegetal, do coeficiente de extinção da cultura e do índice de área foliar. A intensidade da radiação incidente é determinada pelas características do local como a latitude, ângulo de exposição das folhas, pela duração do dia, pela nebulosidade e pela época do ano.

Quanto ao caractere número de ramificações final, a análise de variância revelou efeitos significativos para o fator densidade e espaçamento na primeira época de semeadura, sendo altamente 
significativo $(\mathrm{P}<0,01)$ para o contraste entre os arranjos estudados e o tratamento do agricultor. $\mathrm{Na}$ segunda época, apenas houve significância $(P<0,01)$ para o fator densidade.

Verifica-se ainda, na tabela 6 , que no arranjo de 5 plantas $\mathrm{m}^{-1} \times 0,80 \mathrm{~m}$ entre linhas, há menor número de plantas por área $\left(6 \mathrm{~m}^{-2}\right)$ e maior valor médio de ramificações nas duas épocas estudadas, diferindo significativamente das demais; na primeira época de semeadura, o número de ramificações foram menores que os obtidos na segunda época, em todos os arranjos estudados. Esses resultados têm sustentação em trabalhos similares realizados por Pеіхото et al. (2002), que observaram decréscimo no número de ramificações em função de épocas de semeaduras diferentes, indicando ser essa característica bastante afetada pelas práticas de manejo. Dessa forma, pode-se inferir que as plantas nessa densidade, por ter maior área de exploração do substrato ecológico, permitiram a maior penetração da radiação solar, intensificando sua fotossíntese e possibilitando, conseqüentemente, a maior emissão de ramificações.

Tabela 5. Valores médios (cm) para altura final (AFP) de plantas de amendoim submetidas a diferentes arranjos espaciais (densidades $x$ espaçamentos) em duas épocas de semeadura, no Recôncavo Baiano

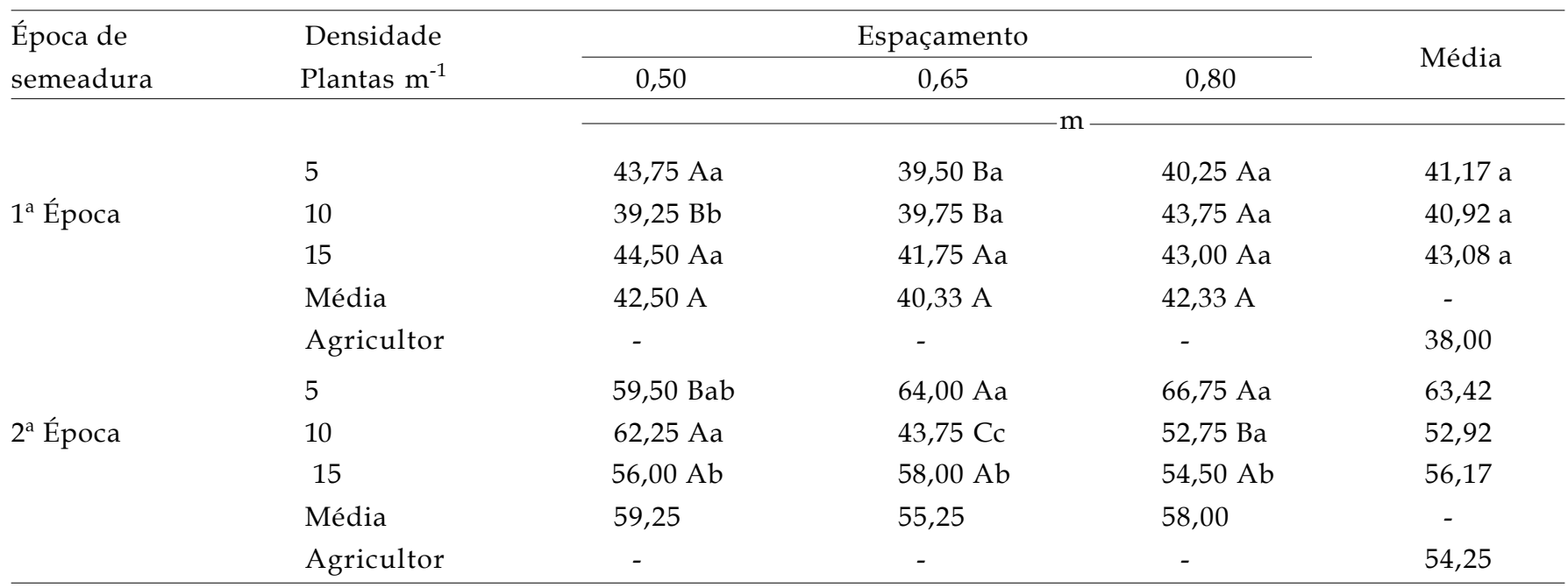

Médias seguidas pela mesma letra minúscula na vertical e maiúscula na horizontal não diferem estatisticamente entre si pelo teste de tukey a $5 \%$ de probabilidade.

Tabela 6. Valores médios do número de ramificações finais (NRF) de plantas de amendoim submetidas a diferentes arranjos espaciais (densidades $x$ espaçamentos) em duas épocas de semeadura, no Recôncavo Baiano

\begin{tabular}{|c|c|c|c|c|c|}
\hline \multirow{2}{*}{$\begin{array}{l}\text { Época de } \\
\text { semeadura }\end{array}$} & \multirow{2}{*}{$\begin{array}{l}\text { Densidade } \\
\text { Plantas } \mathrm{m}^{-1}\end{array}$} & \multicolumn{3}{|c|}{ Espaçamento } & \multirow{2}{*}{ Média } \\
\hline & & 0,50 & 0,65 & 0,80 & \\
\hline \multirow{5}{*}{$1^{\mathrm{a}}$ Época } & 5 & $4,72 \mathrm{Bb}$ & 5,07 Aba & $5,35 \mathrm{Aa}$ & $5,05 \mathrm{a}$ \\
\hline & 10 & $4,60 \mathrm{Aa}$ & 4,75 Аa & $4,82 \mathrm{Ab}$ & $4,72 \mathrm{a}$ \\
\hline & 15 & $4,47 \mathrm{Ab}$ & $4,87 \mathrm{Aa}$ & 4,62 Aab & $4,65 \mathrm{a}$ \\
\hline & Média & $4,60 \mathrm{~A}$ & $4,90 \mathrm{~A}$ & $4,93 \mathrm{~A}$ & - \\
\hline & Agricultor & - & - & - & 5,35 \\
\hline \multirow{5}{*}{$2^{\text {a Época }}$} & 5 & 4,97 Ba & $5,22 \mathrm{Ba}$ & 5,55 Аa & $5,25 \mathrm{a}$ \\
\hline & 10 & $4,75 \mathrm{Ab}$ & $4,90 \mathrm{Aa}$ & $4,97 \mathrm{Ab}$ & $4,87 \mathrm{a}$ \\
\hline & 15 & $4,60 \mathrm{Bb}$ & $4,97 \mathrm{Aa}$ & $4,72 \mathrm{ABb}$ & $4,76 \mathrm{a}$ \\
\hline & Média & $4,77 \mathrm{~A}$ & $5,03 \mathrm{~A}$ & $5,08 \mathrm{~A}$ & - \\
\hline & Agricultor & - & - & - & 5,22 \\
\hline
\end{tabular}

Médias seguidas pela mesma letra minúscula na vertical e maiúscula na horizontal não diferem estatisticamente entre si pelo teste de Tukey a $5 \%$ de probabilidade. 
Para o número de folhas por planta, a análise de variância revelou um efeito altamente significativo $(\mathrm{P}<0,01)$ para o fator densidade em ambas as épocas estudadas (Tabela 7). Entretanto, na segunda época este efeito foi significativo $(P<0,05)$ quando comparou o contraste entre todos os arranjos estudados com o tratamento do agricultor. Os valores médios observados na tabela 7 revelam que a densidade de 5 plantas $\mathrm{m}^{-1}$ obteve maior número de folhas, indiferentemente da época estudada. Apesar de na análise de variância não haver diferenças significativas entre os espaçamentos, a combinação com o espaçamento de $0,65 \mathrm{~m}$ entre linhas na primeira época, e com o de $0,80 \mathrm{~m}$ entre linhas na segunda época, resultou em maiores numero de folhas, diferindo das demais densidades.

Pelos dados obtidos, à medida que aumenta o número de plantas na linha, há forte tendência à redução do número médio de folhas na planta e, conseqüentemente, da sua área foliar. Esses resultados concordam com os dados de PEIXOTO (1998), quando observou que a área foliar da planta de soja diminuiu proporcionalmente com o aumento da densidade na linha de semeadura. A redução no número de folhas das plantas com densidades maiores pode ter ocorrido devido ao auto-sombreamento causado pelo maior número de folhas nas populações de planta mais elevadas, por diminuição do número de ramificações, inclusive.

Tabela 7. Valores médios do número de folhas (NF) de plantas de amendoim submetidas a diferentes arranjos espaciais (densidades $x$ espaçamentos) em duas épocas de semeadura, no Recôncavo Baiano.

\begin{tabular}{|c|c|c|c|c|c|}
\hline \multirow{2}{*}{$\begin{array}{l}\text { Época de } \\
\text { semeadura }\end{array}$} & \multirow{2}{*}{$\begin{array}{l}\text { Densidade } \\
\text { Plantas } \mathrm{m}^{-1}\end{array}$} & \multicolumn{3}{|c|}{ Espaçamento } & \multirow{2}{*}{ Média } \\
\hline & & 0,50 & 0,65 & 0,80 & \\
\hline & & & 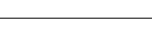 & 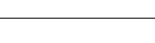 & 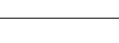 \\
\hline \multirow{5}{*}{$1^{\mathrm{a}}$ Época } & 5 & $11,68 \mathrm{Aa}$ & $12,80 \mathrm{Aa}$ & $11,55 \mathrm{Aa}$ & $12,01 \mathrm{a}$ \\
\hline & 10 & $7,22 \mathrm{Bb}$ & $9,99 \mathrm{Ab}$ & $9,32 \mathrm{Ab}$ & $8,84 \mathrm{~b}$ \\
\hline & 15 & 7,78 Ab & $8,20 \mathrm{Ab}$ & $7,93 \mathrm{Ab}$ & $7,97 \mathrm{~b}$ \\
\hline & Média & $8,89 \mathrm{~A}$ & $10,33 \mathrm{~A}$ & $9,60 \mathrm{~A}$ & - \\
\hline & Agricultor & - & - & - & 9,86 \\
\hline \multirow{5}{*}{$2^{a}$ Época } & 5 & $16,24 \mathrm{Aa}$ & $16,39 \mathrm{Aa}$ & $17,02 \mathrm{Aa}$ & $16,55 \mathrm{a}$ \\
\hline & 10 & $8,38 \mathrm{Ab}$ & $10,15 \mathrm{Ab}$ & $10,53 \mathrm{Ab}$ & $9,69 \mathrm{~b}$ \\
\hline & 15 & $7,45 \mathrm{Ab}$ & 7,71 Ac & $8,79 \mathrm{Ab}$ & $7,98 \mathrm{~b}$ \\
\hline & Média & $10,69 \mathrm{~A}$ & $11,42 \mathrm{~A}$ & $12,11 \mathrm{~A}$ & - \\
\hline & Agricultor & - & - & - & 14,37 \\
\hline
\end{tabular}

Médias seguidas pela mesma letra minúscula na vertical e maiúscula na horizontal não diferem estatisticamente entre si pelo teste de Tukey a $5 \%$ de probabilidade.

Quanto à característica volume de vagem fresca em $\mathrm{L} \mathrm{m}^{-2}$, a análise de variância revelou efeitos altamente significativos $(\mathrm{P}<0,01)$ para os fatores densidade e espaçamento de plantas na primeira época de semeadura, para densidade e para o contraste entre os arranjos espaciais e o tratamento testemunha, na segunda época. Observa-se na tabela 8 que os espaçamentos diferiram significativamente na primeira época de semeadura, sendo o de $0,50 \mathrm{~m}$ entrelinhas, superior aos demais, o mesmo não ocorrendo para a segunda época, quando se observaram diferenças significativas para o espaçamento de $0,80 \mathrm{~m}$ entre linhas, sendo superior, nas densidades de 5 e 10 plantas por metro.

A densidade de 10 plantas $\mathrm{m}^{-1}$, na média, foi a melhor para este caractere resultando em maiores valores, muito embora tenha diferido apenas da menor densidade estudada, na primeira época de semeadura, revelando-se também superior ao tratamento do agricultor (Tabela 8 ), que obteve médias inferiores a quase todos os arranjos espaciais, nas condições ambientais da primeira época de semeadura.

A comparação dos arranjos para a variável volume de vagens frescas na segunda época também revelou efeitos altamente significativos, para o fator densidade como também mostra que houve significância no contraste entre os demais arranjos e o tratamento do agricultor (13 plantas $\mathrm{m}^{-2}$ ), sendo superior aos demais tratamentos, diferindo estatisticamente pelo teste de Dunnett (Tabela 9), com exceção do arranjo de 5 plantas $\mathrm{m}^{-1} \times 0,80 \mathrm{~m}\left(6\right.$ plantas $\left.\mathrm{m}^{-2}\right)$. Esta é uma variável de grande importância para o agricultor, porque se comercializa o produto no campo e nas feiras livres, baseando-se no volume das vagens. 
Tabela 8. Valores médios do volume $\left(\mathrm{L} \mathrm{m}^{2}\right)$ de vagens frescas (VVF) de plantas de amendoim submetidas a diferentes arranjos espaciais (densidades $\mathrm{x}$ espaçamentos) em duas épocas de semeadura, no Recôncavo Baiano.

\begin{tabular}{|c|c|c|c|c|c|}
\hline \multirow{2}{*}{$\begin{array}{l}\text { Época de } \\
\text { semeadura }\end{array}$} & \multirow{2}{*}{$\begin{array}{l}\text { Densidade } \\
\text { Plantas } \mathrm{m}^{-1}\end{array}$} & \multicolumn{3}{|c|}{ Espaçamento } & \multirow{2}{*}{ Média } \\
\hline & & 0,50 & 0,65 & 0,80 & \\
\hline \multirow{5}{*}{$1^{\mathrm{a}}$ Época } & 5 & $0,81 \mathrm{Ab}$ & 0,67 Bb & $0,65 \mathrm{Bb}$ & $0,71 \mathrm{~b}$ \\
\hline & 10 & $1,13 \mathrm{Aa}$ & $0,92 \mathrm{Ba}$ & 0,85 Ba & $0,97 \mathrm{a}$ \\
\hline & 15 & $1,09 \mathrm{Aa}$ & 0,94 Ba & 0,81 Ca & 0,95 a \\
\hline & Média & $1,01 \mathrm{~A}$ & $0,84 \mathrm{AB}$ & 0,77 B & - \\
\hline & Agricultor & - & - & - & 0,78 \\
\hline \multirow{5}{*}{$2^{\mathrm{a}}$ Época } & 5 & $1,27 \mathrm{Ba}$ & $1,20 \mathrm{Ba}$ & $1,57 \mathrm{Aa}$ & $1,34 \mathrm{a}$ \\
\hline & 10 & $0,96 \mathrm{~B} \mathrm{~b}$ & $0,98 \mathrm{Aba}$ & $1,21 \mathrm{Ab}$ & $1,05 \mathrm{a}$ \\
\hline & 15 & $0,88 \mathrm{Ac}$ & 1,04 Aa & $0,99 \mathrm{Ab}$ & $0,97 a$ \\
\hline & Média & $1,03 \mathrm{~A}$ & $1,07 \mathrm{~A}$ & $1,25 \mathrm{~A}$ & - \\
\hline & Agricultor & - & - & - & 1,83 \\
\hline
\end{tabular}

Médias seguidas pela mesma letra minúscula na vertical e maiúscula na horizontal não diferem estatisticamente entre si pelo teste de Tukey a $5 \%$ de probabilidade.

Sabe-se que um dos fatores que onera a produção de amendoim no Recôncavo Baiano é o preço da aquisição das sementes. Dessa forma, o produtor perde ao optar pelo arranjo convencional $\left(025 \times 0,30 \mathrm{~m}^{-2}\right)$ porque ele terá que adquirir cerca de duas vezes mais o número de semente para a semeadura, se comparado com o arranjo de 5 plantas $\mathrm{m}^{-1} \times 0,80 \mathrm{~m}$, cultivando na segunda época. Além disso, segundo Pегхото (1998) as menores densidades facilitam os tratos culturais e a colheita da cultura.

A análise de variância revelou efeitos altamente significativos $(\mathrm{P}<0,01)$ nos caracteres produtividade de vagens e produtividade de grãos, nas duas épocas em estudo, para os fatores densidades e espaçamento, sendo este mesmo efeito verificado para a interação densidade $x$ espaçamento e ao contraste dos fatores versus tratamento do agricultor, quando se avaliou a segunda época.

O detalhamento dos contrastes (Tabela 9) revelou uma superioridade na maioria dos tratamentos estudados sobre o arranjo espacial do agricultor na primeira época de semeadura, para a produtividade de vagens, apresentando significância apenas nos arranjos $\mathrm{D}_{2} \mathrm{E}_{1}$ e $\mathrm{D}_{3} \mathrm{E}_{2}$. Entretanto, esse fato não se verificou quando se avaliou a produtividade de grãos em que a maioria dos tratamentos foi inferior à testemunha, mesmo sem haver diferenças significativas. No entanto, na segunda época de semeadura, houve total supremacia dos diferentes arranjos espaciais, em ambas as características, sobre o tratamento do agricultor, com alguns diferindo significativamente, significando que neste tratamento as plantas não realizaram boa conversão da matéria seca em vagens e grãos, na mesma proporção em que foi convertida na primeira época.

Nas tabelas 10 e 11, relacionam-se os valores médios da produtividade de vagens e grãos em $(\mathrm{kg}$ $\mathrm{ha}^{-1}$ ) para as duas épocas de semeadura. Nota-se que no arranjo de 10 plantas $^{-1} \times 0,50 \mathrm{~m}$ entre linhas a média foi superior aos demais, diferindo significativamente de outros espaçamentos e da menor densidade na primeira época, além da superioridade na densidade de 15 plantas por metro no espaçamento de $0,80 \mathrm{~m}$ entre as linhas de semeadura. Na segunda época de semeadura, o tratamento que se destacou com maiores valores médios foi o de 15 plantas $^{-1} \times 0,50 \mathrm{~m}$, diferindo significativamente dos demais, tanto no fator densidade quanto no espaçamento.

Pode-se observar que, para as duas épocas de semeadura, à medida que se diminui o espaçamento há aumento na produtividade de vagens e grãos. ARF et al. (1991) também observaram que com a redução do espaçamento nas entrelinhas da cultura houve aumento na produtividade de vagens e grãos.

Os valores observados nas duas épocas de semeadura permitem perceber nitidamente a superioridade da segunda época em relação à primeira (Tabela 10). É possível que esses valores tenham sido determinados pelas condições ambientais predominantes nas diferentes épocas estudadas, interferindo nas fases fenológicas da planta e nos diferentes arranjos espaciais, com reflexos no desenvolvimento vegetativo e nos componentes de produção da planta, influenciando na variação da produtividade final, com prejuízo da primeira época. 
Tabela 9. Diferenças médias entre os arranjos espaciais e o tratamento adicional para altura final de planta (AFP), número de ramificações final (NRF), número de folhas (NF), volume de vagens frescas (VVF), rendimento de vagens $(\mathrm{RV})$ e grãos (RG) de plantas de amendoim submetidas a diferentes arranjos espaciais (densidades $x$ espaçamentos) em duas épocas de semeadura, no Recôncavo Baiano

\begin{tabular}{|c|c|c|c|c|c|c|}
\hline $\begin{array}{l}\text { Comparações } \\
\text { (Trat. vs test.) }\end{array}$ & AFP & NRF & NF & VVF & RV & RG \\
\hline & $\mathrm{cm}$ & 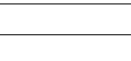 & 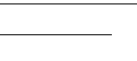 & $\mathrm{L} \mathrm{m}^{2}$ & 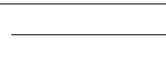 & \\
\hline \multicolumn{7}{|l|}{ 1. ${ }^{a}$ Época } \\
\hline (D1 E1) - 0 & $5,750^{\mathrm{ns}}$ & $-0,62^{\mathrm{ns}}$ & $1,82^{\mathrm{ns}}$ & $0,03^{\mathrm{ns}}$ & $262,00^{\mathrm{ns}}$ & $-48,50^{\mathrm{ns}}$ \\
\hline (D1 E2) - 0 & $1,500^{\mathrm{ns}}$ & $-0,27^{\mathrm{ns}}$ & $2,94^{\mathrm{ns}}$ & $-0,11^{\mathrm{ns}}$ & $-188,30^{\mathrm{ns}}$ & $-315,50^{\mathrm{ns}}$ \\
\hline (D1 E3) - 0 & $2,250^{\mathrm{ns}}$ & $0,00{ }^{\mathrm{ns}}$ & $1,69^{\mathrm{ns}}$ & $-0,13^{\mathrm{ns}}$ & $-245,10^{\mathrm{ns}}$ & $-310,1^{\mathrm{ns}}$ \\
\hline (D2 E1) - 0 & $1,250^{\mathrm{ns}}$ & $-0,75^{* *}$ & $-2,64^{\mathrm{ns}}$ & $0,34^{* *}$ & $571,30 * *$ & $228,5^{\mathrm{ns}}$ \\
\hline$(\mathrm{D} 2 \mathrm{E} 2)-0$ & $1,750^{\mathrm{ns}}$ & $-0,60^{\mathrm{ns}}$ & $0,130^{\mathrm{ns}}$ & $0,14^{\mathrm{ns}}$ & $210,70^{\mathrm{ns}}$ & $-2,30^{\mathrm{ns}}$ \\
\hline (D2 E3) - 0 & $5,750^{\mathrm{ns}}$ & $-0,52^{\mathrm{ns}}$ & $-0,54^{\mathrm{ns}}$ & $0,07^{\mathrm{ns}}$ & $110,40^{\mathrm{ns}}$ & $-92,80^{\mathrm{ns}}$ \\
\hline (D3 E1) - 0 & $6,500^{\mathrm{ns}}$ & $-0,87^{* *}$ & $-2,08^{n s}$ & $0,31^{* *}$ & $499,50 * *$ & $205,00^{\mathrm{ns}}$ \\
\hline (D3 E2) - 0 & $5,00^{\mathrm{ns}}$ & $-0,47^{\mathrm{ns}}$ & $-1,66^{\mathrm{ns}}$ & $0,15^{\mathrm{ns}}$ & $234,8^{\mathrm{ns}}$ & $-38,5^{\mathrm{ns}}$ \\
\hline (D3 E3) - 0 & $3,750^{\mathrm{ns}}$ & $-0,72^{* *}$ & $-1,93^{\mathrm{ns}}$ & $0,02^{\mathrm{ns}}$ & $-51,7^{\mathrm{ns}}$ & $-178,2^{\mathrm{ns}}$ \\
\hline \multicolumn{7}{|l|}{ 2. a Época } \\
\hline (D1 E1) - 0 & $5,250^{\mathrm{ns}}$ & $-0,25^{\mathrm{ns}}$ & $1,87^{\mathrm{ns}}$ & $-0,55^{* *}$ & $444,00^{\mathrm{ns}}$ & $281,3^{\mathrm{ns}}$ \\
\hline (D1 E2) - 0 & $9,750 * *$ & $0,00^{\mathrm{ns}}$ & $2,02^{\mathrm{ns}}$ & $-0,62^{* *}$ & $357,20^{\mathrm{ns}}$ & $200,1^{\mathrm{ns}}$ \\
\hline (D1 E3) - 0 & $12,500 * *$ & $0,32^{\mathrm{ns}}$ & $2,65^{\mathrm{ns}}$ & $-0,26^{\mathrm{ns}}$ & $203,30^{\mathrm{ns}}$ & $420,90^{\mathrm{ns}}$ \\
\hline (D2 E1) - 0 & $8,000 * *$ & $-0,47^{\mathrm{ns}}$ & $-5,99 * *$ & $-0,86^{* *}$ & $934,60 * *$ & $646,40^{* *}$ \\
\hline$(\mathrm{D} 2 \mathrm{E} 2)-0$ & $10,500^{* *}$ & $-0,32^{\mathrm{ns}}$ & $-4,22^{\mathrm{ns}}$ & $-0,84^{* *}$ & $175,90^{\mathrm{ns}}$ & $90,60^{\mathrm{ns}}$ \\
\hline (D2 E3) - 0 & $-1,500^{\mathrm{ns}}$ & $-0,25^{\mathrm{ns}}$ & $-3,84^{\mathrm{ns}}$ & $-0,61^{* *}$ & $404,5^{\mathrm{ns}}$ & $626,70^{* *}$ \\
\hline (D3 E1) - 0 & $1,750^{\mathrm{ns}}$ & $-0,62^{\mathrm{ns}}$ & $-6,92^{* *}$ & $-0,95^{\star *}$ & $1570,20^{* *}$ & $1142,00^{* *}$ \\
\hline (D3 E2) - 0 & $3,750^{\mathrm{ns}}$ & $-0,25^{\mathrm{ns}}$ & $-6,66^{* *}$ & $-0,79 * *$ & $542,30^{* *}$ & $357,50^{\mathrm{ns}}$ \\
\hline (D3 E3) - 0 & $0,250^{\mathrm{ns}}$ & $-0,50^{\mathrm{ns}}$ & $-5,58^{* *}$ & $-0,83^{* *}$ & $3,30^{\mathrm{ns}}$ & $274,30^{\mathrm{ns}}$ \\
\hline
\end{tabular}

**Significativo a $5 \%$ de probabilidade pelo teste $\mathrm{t}$ de Dunnett; ${ }^{\text {ns }}$ não significativo; $\mathrm{D} 1=5$ plantas $\mathrm{m}^{-1} ; \mathrm{D} 2=10 \mathrm{plantas}^{-1}$; $\mathrm{D} 3=15 \mathrm{plantas} \mathrm{m}^{-}$ 1 ; $\mathrm{E} 1=0,50 \mathrm{~m} ; \mathrm{E} 2=0,65 \mathrm{~m} ; \mathrm{E} 3=0,80 \mathrm{~m} ; 0=(0,25 \mathrm{~m} \times 0,30 \mathrm{~m})$.

No que diz respeito à produtividade alcançada pelos diferentes arranjos espaciais (Tabelas 10 e 11), os resultados permitem indicar que, para cada época estudada, houve um arranjo com maior valor de produtividade de vagens e grãos, sendo a combinação $\mathrm{D}_{2} \mathrm{E}_{1}\left(10\right.$ plantas $\left.\mathrm{m}^{-1} \times 0,50 \mathrm{~m}\right)$ melhor na primeira época e $\mathrm{D}_{3} \mathrm{E}_{1}\left(15\right.$ plantas $\left.\mathrm{m}^{-1} \times 0,50 \mathrm{~m}\right)$, na época seguinte. Desta forma, o agricultor dispõe de dois arranjos espaciais que poderá optar em conformidade à época de semeadura que escolher.

Se o produtor na primeira época, objetivando a produtividade de vagens, optar pelo arranjo de 10 plantas $\mathrm{m}^{-1} \times 0,50 \mathrm{~m}$ ao invés do arranjo de 15 plantas $\mathrm{m}^{-1} \times 0,50$ $\mathrm{m}$, embora não verifiquem diferenças significativas (Tabela 10), haverá uma diferença de 100.000 plantas a menos por hectare e cerca de $70 \mathrm{~kg} \mathrm{ha}^{-1}$ a mais, na produtividade de vagens em favor do primeiro. Quando comparado ao tratamento do agricultor, serão 67.000 plantas a mais por hectare, porém com uma diferença significativa $(P<0,01)$ de aproximadamente $570 \mathrm{~kg} \mathrm{ha}^{-1}$ na produtividade, o que compensaria seguramente sua escolha.
Para a segunda época, não caberia esta comparação, pois o arranjo de 15 plantas $\mathrm{m}^{-1} \times 0,50 \mathrm{~m}$ (303.000 plantas ha ${ }^{-1}$ ) diferiu estatisticamente do arranjo de 10 plantas $\mathrm{m}^{-1} \times 0,50 \mathrm{~m}$ (200.000 plantas ha${ }^{1}$ ), como também do tratamento do agricultor (Tabela 9), com uma população de 133.000 plantas ha- ${ }^{-1}$. Em que pese o maior número de plantas por hectare, a combinação $\mathrm{D}_{3} \mathrm{E}_{1}$, tem uma diferença na produtividade de $635 \mathrm{~kg} \mathrm{ha}^{-1}$ comparado ao $\mathrm{D}_{2} \mathrm{E}_{1}$ e de $1570 \mathrm{~kg} \mathrm{ha}^{-1}$ ao do agricultor, mostrando a superioridade daquele arranjo, nessa época de semeadura.

Estes resultados evidenciam que a busca de novas alternativas de cultivo, com a utilização de novos arranjos espaciais, se faz necessário, uma vez que, como demonstrado nesse trabalho, pode não ser economicamente viável para o produtor de amendoim do Recôncavo Baiano, semear convencionalmente, na configuração de semeadura em covas $(0,25 \mathrm{~m} \times 0,30 \mathrm{~m})$, nas duas estações de crescimento estudadas. 
Tabela 10. Valores médios da produtividade de vagens $\left(\mathrm{kg} \mathrm{h}^{-1}\right)$ em plantas de amendoim submetidas a diferentes arranjos espaciais (densidades $x$ espaçamentos) em duas épocas de semeadura, no Recôncavo Baiano

\begin{tabular}{|c|c|c|c|c|c|}
\hline \multirow{2}{*}{$\begin{array}{l}\text { Época de } \\
\text { semeadura }\end{array}$} & \multirow{2}{*}{$\begin{array}{l}\text { Densidade } \\
\text { Plantas } \mathrm{m}^{-1}\end{array}$} & \multicolumn{3}{|c|}{ Espaçamento } & \multirow{2}{*}{ Média } \\
\hline & & 0,50 & 0,65 & 0,80 & \\
\hline \multicolumn{6}{|c|}{$-\mathrm{m}-$} \\
\hline \multirow{5}{*}{$1^{\mathrm{a}}$ Época } & 5 & $1815,62 \mathrm{Ab}$ & $1365,35 \mathrm{Bb}$ & $1308,57 \mathrm{Bb}$ & $1496,51 \mathrm{a}$ \\
\hline & 10 & $2125,00 \mathrm{Aa}$ & $1764,40 \mathrm{Ba}$ & $1664,06 \mathrm{Ba}$ & $1851,15 \mathrm{a}$ \\
\hline & 15 & $2053,12 \mathrm{Aa}$ & $1788,45 \mathrm{Ba}$ & $1501,96 \mathrm{Bab}$ & $1781,18 \mathrm{a}$ \\
\hline & Média & $1997,91 \mathrm{~A}$ & $1639,40 \mathrm{AB}$ & 1491,53 B & - \\
\hline & Agricultor & - & - & - & 1556,66 \\
\hline \multirow{5}{*}{$2^{\mathrm{a}}$ Época } & 5 & 2303,13 Ac & $2216,34 \mathrm{Aab}$ & $2062,12 \mathrm{Aab}$ & 2193,86 \\
\hline & 10 & $2793,75 \mathrm{Bb}$ & $2035,10 \mathrm{Ab}$ & $2263,67 \mathrm{Aa}$ & 2364,17 \\
\hline & 15 & $3429,37 \mathrm{Aa}$ & $2401,44 \mathrm{Ba}$ & $1862,50 \mathrm{Cb}$ & 2564,43 \\
\hline & Média & 2842,08 & 2217,62 & 2062,76 & - \\
\hline & Agricultor & - & - & - & 1859,16 \\
\hline
\end{tabular}

Médias seguidas pela mesma letra minúscula na vertical e maiúscula na horizontal não diferem estatisticamente entre si pelo teste de Tukey a $5 \%$ de probabilidade.

Tabela 11. Valores médios da produtividade de grãos ( $\mathrm{kg} \mathrm{ha}$ ) em plantas de amendoim submetidas a diferentes arranjos espaciais (densidades $x$ espaçamentos) em duas épocas de semeadura no Recôncavo Baiano

\begin{tabular}{|c|c|c|c|c|c|}
\hline \multirow{2}{*}{$\begin{array}{l}\text { Época de } \\
\text { semeadura }\end{array}$} & \multirow{2}{*}{$\begin{array}{l}\text { Densidade } \\
\text { Plantas } \mathrm{m}^{-1}\end{array}$} & \multicolumn{3}{|c|}{ Espaçamento } & \multirow{2}{*}{ Média } \\
\hline & & 0,50 & 0,65 & 0,80 & \\
\hline \multirow{6}{*}{$1^{\text {a }}$ Época } & n. ${ }^{\circ}$ & - & +2 & 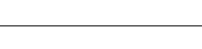 & \\
\hline & 5 & $1160,19 \mathrm{Ab}$ & $893,14 \mathrm{Ab}$ & $898,62 \mathrm{Ab}$ & $983,98 \mathrm{a}$ \\
\hline & 10 & $1437,17 \mathrm{Aa}$ & $1206,38 \mathrm{ABab}$ & $1115,85 \mathrm{Bb}$ & $1253,13 \mathrm{a}$ \\
\hline & 15 & $1413,65 \mathrm{Aa}$ & $1170,22 \mathrm{ABa}$ & $1030,43 \mathrm{Ba}$ & $1204,77 \mathrm{a}$ \\
\hline & Média & $1337,00 \mathrm{~A}$ & $1089,91 \mathrm{AB}$ & 1014,97 B & - \\
\hline & Agricultor & - & - & - & 1208,67 \\
\hline \multirow{5}{*}{$2^{\mathrm{a}}$ Época } & 5 & 1584,93 Ас & $1503,74 \mathrm{Aab}$ & $1724,51 \mathrm{Aab}$ & 1604,39 \\
\hline & 10 & $1950,00 \mathrm{Ab}$ & $1394,23 \mathrm{Bb}$ & $1930,28 \mathrm{Aa}$ & 1933,28 \\
\hline & 15 & 2445,62 Aa & $1661,06 \mathrm{Ba}$ & $1577,88 \mathrm{Bb}$ & 1894,85 \\
\hline & Média & 1993,51 & 1519,67 & 1744,22 & - \\
\hline & Agricultor & - & - & - & 1303,61 \\
\hline
\end{tabular}

Médias seguidas pela mesma letra minúscula na vertical e maiúscula na horizontal não diferem estatisticamente entre si pelo teste de Tukey a $5 \%$ de probabilidade.

\section{CONCLUSÕES}

1. Independentemente da densidade de plantas ou do espaçamento utilizado, a época de semeadura é o fator que mais influencia nas características agronômicas e na produtividade de vagens e grãos do amendoim cultivado no Recôncavo Baiano.

2. A escolha do arranjo espacial que expressa maiores produtividades de vagens e de grãos depende do objetivo comercial do produtor (volume ou massa) e da época de semeadura.
3. A utilização de novos arranjos espaciais pelos agricultores do Recôncavo Baiano, se faz necessária, uma vez que a semeadura em covas de $0,25 \mathrm{~m} \times 0,30 \mathrm{~m}$, é menos produtiva, nas duas épocas de semeadura.

\section{REFERÊNCIAS}

ALMEIDA, O.A. Informações metereológicas do CNP: Mandioca e Fruticultura tropical. Cruz das Almas, BA: EMBRAPA - CNPMF, 1999. 35p. (EMBRAPA - CNPMF. Documentos, 34) 
ARF, O. ATHAYDE, M.L.F.; MALHEIROS, E.B. Comportamento do amendoim (Arachis hypogaea L.) com diferentes densidades de planta, em área de renovação de canavial. Científica, São Paulo, v.19, n.2, p.9-18, 1991.

BARNI, N.A.; BERGAMASCHI, H. Alguns princípios técnicos para a semeadura. In: MIYASAKA, S.; MEDINA, J.L. A soja no Brasil. Campinas, 1981. p.476-480.

BRASIL. Ministério da Agricultura. Regras para análise de sementes. Brasília: LANARV, SNDA, 1992. 365p.

CÂMARA, G. M. S. Desempenho produtivo das cultivares de soja IAC-12, IAC-17 e IAC-19 em três épocas de semeadura e cinco densidades de plantas.1998. 165p. Tese (Livre Docente) Escola Superior de Agricultura "Luiz de Queiroz", Universidade de São Paulo, Piracicaba.

CHOUDHARI, S.D.; UDAYKUMAR, M.; SASTRY, K.S.K. Physiology of bunch groundnuts (Arachis hypogaea L.). Journal of Agricultural Science, Cambridge, v.104, p.309315, 1985.

CONAGIN, C.H.T.M.; CONAGIN, A. Eficiência reprodutiva do amendoim cultivado (Arachis hypogaea L.). Bragantia, Piracicaba, v.102, n.65, p.1081-1104, 1960.

HEIFFIG, L.S. Plasticidade da cultura da soja (Glycyne max (L.) Merrill) em diferentes arranjos espaciais. 2000. 85p. Dissertação (Mestrado em Fitotecnia) - Escola Superior de Agricultura "Luiz de Queiroz", Universidade de São Paulo, Piracicaba.

HENRIQUES NETO, D.H.; TAVORA, F.J.A.F.; SILVA, F.P. ; SANTOS, M.A.; MELO, F.I.O. Componentes de produção e produtividade do amendoim submetido a diferentes populações e configurações de semeadura. Revista de Oleaginosas e Fibrosas, Capina Grande, v. 2, n.2. p. 113122, 1998.

HORN, F.L.; SCHUCH, L.O.B.; SILVEIRA, E.P.; ANTUNES, I.F.; VIEIRA, J.C.;MARCHIORO, G.; MEDEIROS, D.F.; SCHWENGBER, J.E. Avaliação de espaçamentos e populações de plantas de feijão visando à colheita mecanizada direta. Pesquisa Agropecuária Brasileira, Brasília, v. 35, n.1, p.15471555,2000 .

KASAI, F.S.; PAULO, E.M. GODOY, I.J.; NAGAI, V. Influencia da época de semeadura no crescimento, produtividade e outros fatores de produção em cultivares de amendoim na região da Alta Paulista. Bragantia, Campinas, v.58, n.1, p.100-112. 1999.

LIMA, C.A.S.; SILVA, L.; Marinato, R.; Época de semeadura, densidade e irrigação do amendoim. Informe Agropecuário, Belo Horizonte, v. 7, n. 82, p. 52-53, 1981.

MOZINGO, R.W.; WRIGHT, F.S. Diamond-shaped seeding of six peanut cultivars. Peanut Science, Perkins, v. 21, n.1, p.5-9, 1994.

NAKAGAWA, J.; LASCA, D.H.C.; NEVES, J.P.S.; NEVES, G.S.; SILVA, M.N.;SANCHES, S.V.; BARBOSA, V.; ROSSETO, C.A.V. Densidades de plantas e produção de amendoim. Scientia Agrícola, Piracicaba, V.57, n.1, p.67-73, 2000.
NAKAGAWA, J.; LASCA, D.H.C.; NEVES, J.P.S.; NEVES, G.S.; SANCHES,S.V.;BARBOSA, V.; SILVA, M. N. ; ROSSETO, C.A. V. Efeito da densidade de semeadura na produção do amendoim. Pesquisa Agropecuária Brasileira, Brasília, v.29, n.10, p.1547-1555, 1994.

PEIXOTO, C. P. Análise de crescimento e produtividade de três cultivares de soja em três épocas de semeadura e três densidades de plantas. 1998. 151f. Tese (Doutorado em Fitotecnia), Escola Superior de Agricultura "Luiz de Queiroz", Universidade de São Paulo, Piracicaba.

PEIXOTO, C.P.; CAMARA G.M.S.; MARTINS, M.C.; MARCHIORI, L.F.S. Efeitos de épocas de semeadura e densidade de plantas sobre a produtividade de cultivares de soja no Estado de São Paulo. Revista de Agricultura, Piracicaba, v.77, n. 2, p.265-291, 2002.

REZENDE, J.O. Solos coesos dos tabuleiros costeiros: limitações agrícolas e manejo. Salvador: SEAGRI-SPA, 2000. 117p. (Série Estudos Agrícolas)

REICHARDT, K. A água em sistemas agrícolas. São Paulo: Manole, 1990.188p.

SANTOS, R.C.; BRS151 L-7: Nova cultivar de amendoim para as condições do Nordeste brasileiro. Pesquisa Agropecuária Brasileira, Brasília, v. 35, n.3, p.665-670, 2000.

SANTOS, R.C.; MELO FILHO, P.A.; BRITO, S.F.; MORAES, J.S. Fenologia de genótipos de amendoim dos tipos botânicos Valência e Virgínia. Pesquisa Agropecuária Brasileira, Brasília, v. 32, n.6, p.607$612,1997 b$.

SILVA, M.B.; BELTRÃO, N.E.M. Níveis populacionais e configurações de semeadura na cultura do amendoim, em regime de sequeiro na Mesorregião do agreste da Borborema do Estado da Paraíba. Revista de Oleaginosas e Fibrosas, Campina Grande, v.4. n.1, p.23-34, 2000.

UMEN, D.P. Biology of peanut flowering. New Delhi: Amerind, 1976. 77p. 